\title{
On the Correctness of the Statement of Certain Issues in Electrical Engineering
}

\author{
V. P. Belyaev \\ Belarussian State Technological University, Minsk, Belorussia \\ e-mail:journal-elektrotechnika@mail.ru \\ Received March 18, 2014
}

\begin{abstract}
We call attention to an incorrect use of the slip of an asynchronous electric motor as a means for adjusting its speed. A correct approach to the construction of models of a variable-speed electric motor (in particular, in the Matlab-Simulink computational environment) is proposed.
\end{abstract}

Keywords: asynchronous motor, speed adjustment, computation

DOI: $10.3103 / \mathrm{S} 1068371214040026$

It is pointed out in certain sections of scientific and technical books and textbooks dealing with the subject of adjusting the speed of a three-phase cage asynchronous motor that the speed may be adjusted - in particular, by altering the motor slip (see, for example, [1], p. 197). It is known that slip $s=\left(\omega_{0}-\omega_{r}\right) / \omega_{0}$, where $\omega_{0}=2 \pi f_{s}$ is the rotation rate of the stator magnetic field produced by a three-phase ac voltage system with frequency $f_{s}$ applied to asynchronous motor stator windings and $\omega_{r}$ is the rotor speed of the motor. Logical analysis of this expression and an analysis of the electromagnetic processes (producing the slip) of electromechanical transformation of the electrical energy in the asynchronous motor and in the motor as a part of an electric drive allow one to conclude that the slip is the result of the above-mentioned processes (an internal state of the motor). Therefore, the slip may not be used to alter the rotor speed of the motor. The rotor speed may be altered only by certain external (control and disturbing) actions. This is stated clearly in [2] (see p. 520): "control methods are differentiated in the way the motor is influenced: the primary influence may come from (1) the stator side or (2) the rotor side." The same is stated in automatic-control theory.

Another thing worth mentioning is electric-drive modeling (in particular, in the Matlab-Simulink computational environment). Let us discuss this using the example of a model of an electric drive with an asynchronous motor constructed using a standard "asynchronous machine" unit. This designation is incorrect because the inputs of this unit are fed not only with the control actions in the form of a threephase ac voltage, but also with a parameter corresponding to the static resistance moment $\left(T_{m}\right)$. The moment of inertia is one of the values input into the parameter setting window of this unit, and the speed value is found at its output. Therefore, the mathematical model of this unit contains an equation of motion, and the unit itself represents the electric-drive pro- cesses. It is known that any actual electric drive of an industrial mechanism has an idling torque (or an idle load torque). Thus, the electric-drive motion starts only when the mechanical moment (produced by the electric motor) at its shaft exceeds the mentioned torque. Therefore, the model should be dual-structured. The first model structure would represent the processes occurring prior to the start of motion, and the second one would represent the processes occurring in motion. Unfortunately, the models found in scientific and technical literature do not reproduce these details and thus misrepresent electric-drive operation. This inaccuracy may have no effect on the end result on the large scale, but is unacceptable on the small scale, especially when certain units with their parameters determined using the speed value, which equals zero prior to the motion start, are present in direct modeling of the motor equations that describe its electromagnetic processes. A single-structure model yields (in accordance with the equation of motion being solved) a negative speed value at the start of the computation, and the use of these results in other units of the model distorts the numerical results of the end calculations.

We conclude that these inaccuracies should immediately be taken note of, especially in teaching the engineering disciplines.

\section{REFERENCES}

1. Kopylov, I.P., Elektricheskie mashiny (Electrical Machines), Moscow: Energoatomizdat, 1986.

2. Kostenko, M.P. and Piotrovskii, L.M., Elektricheskie mashiny (Electrical Machines), part 2: Mashiny peremennogo toka (AC Electrical Machines), MoscowLeningrad: GEI, 1958. 